\title{
Right versus left radial artery access for coronary procedures: An international collaborative systematic review and meta-analysis including 5 randomized trials and 3210 patients
}

\author{
Giuseppe Biondi-Zoccai a,b,*, Alessandro Sciahbasi ${ }^{\mathrm{c}}$, Vicente Bodí d , Javier Fernández-Portales ${ }^{\mathrm{e}}$, \\ Yumiko Kanei ${ }^{\mathrm{f}}$, Enrico Romagnoli ${ }^{\text {b,c }}$, Pierfrancesco Agostoni ${ }^{\text {b,g, }}$, Giuseppe Sangiorgi ${ }^{\text {b,h }}$, \\ Marzia Lotrionte ${ }^{\mathrm{b}, \mathrm{i}}$, Maria Grazia Modena ${ }^{\mathrm{a}}$ \\ a Division of Cardiology, University of Modena and Reggio Emilia, Modena, Italy \\ ${ }^{\mathrm{b}}$ Meta-analysis and Evidence based medicine Training in Cardiology (METCARDIO), Ospedaletti, Italy \\ c Unità Operativa di Cardiologia, Policlinico Casilino, Rome, Italy \\ d Servicio de Cardiología, Hospital Clínico y Universitario de Valencia, Valencia, Spain \\ e Unidad de Hemodinámica, Clínica Virgen de Guadalupe, IDC Capio, Cáceres, Spain \\ f Division of Cardiology, Department of Medicine, Beth Israel Medical Center, New York, NY, United States \\ ${ }^{g}$ Department of Cardiology, Utrecht University Medical Center, Utrecht, The Netherlands

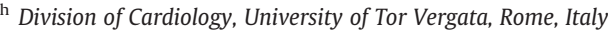 \\ i Heart Failure and Cardiac Rehabilitation Unit, Catholic University of the Sacred Heart, Rome, Italy
}

\section{A R T I C L E I N F O}

\section{Article history:}

Received 6 May 2011

Received in revised form 26 August 2011

Accepted 26 November 2011

Available online 20 December 2011

\section{Keywords:}

Coronary artery disease

Meta-analysis

Radial

Systematic review

\begin{abstract}
A B S T R A C T
Background: Radial artery access is a mainstay in the diagnosis and treatment of coronary artery disease. However, there is uncertainty on the comparison of right versus left radial access for coronary procedures. We thus undertook a systematic review and meta-analysis comparing right versus left radial access for coronary diagnostic and interventional procedures.

Methods: Pertinent studies were searched in CENTRAL, Google Scholar, MEDLINE/PubMed, and Scopus, together with international conference proceedings. Randomized trials comparing right versus left radial (or ulnar) access for coronary diagnostic or interventional procedures were included. Risk ratios (RR) and weighted mean differences (WMD) were computed to generate point estimates (95\% confidence intervals). Results: A total of 5 trials (3210 patients) were included. No overall significant differences were found comparing right versus left radial access in terms of procedural time (WMD $=0.99[-0.53 ; 2.51] \mathrm{min}, \mathrm{p}=0.20)$, contrast use $(\mathrm{WMD}=1.71[-1.32 ; 4.74] \mathrm{mL}, \mathrm{p}=0.27)$, fluoroscopy time $(\mathrm{WMD}=-35.79[-3.54 ; 75.12] \mathrm{s}$, $\mathrm{p}=0.07)$ or any major complication $(\mathrm{RR}=2.00[0.75 ; 5.31], \mathrm{p}=0.49)$. However, right radial access was fraught with a significantly higher risk of failure leading to cross-over to femoral access $(R R=1.65$ [1.18; 2.30], $\mathrm{p}=0.003$ ) in comparison to left radial access.

Conclusions: Right and left radial accesses appear largely similar in their overall procedural and clinical performance during transradial diagnostic or interventional procedures. Nonetheless, left radial access can be recommended especially during the learning curve phase to reduce femoral cross-overs.
\end{abstract}

(C) 2011 Elsevier Ireland Ltd. All rights reserved.

\section{Introduction}

Since the first pioneering experiences [1,2], radial artery access has gained ongoing momentum as a safe and effective approach for diagnostic and interventional procedures in patients with or at risk for coronary artery disease [3]. Indeed, the radial access provides very significant reductions in local access site complications in

\footnotetext{
* Corresponding author at: Division of Cardiology, University of Modena and Reggio Emilia, Via Del Pozzo 71, 41124 Modena, Italy. Tel.: + 39059422 5783; fax: + 39059 4223714 .

E-mail address: gbiondizoccai@gmail.com (G. Biondi-Zoccai).
}

comparison to brachial or femoral access, at the price of a lower access site success (but not overall procedural success) [3-5]. Similar benefits and drawbacks have been reported for the ulnar artery access [6,7].

Despite such evidence in favor of the radial access, especially in patients with acute myocardial infarction [3-5,8], operators wishing to adopt this approach remain uncertain on which radial artery is best. In fact, limited evidence and conflicting trials have been reported on the comparison of right versus left radial access in patients undergoingcoronary procedures $[9,10]$.

As systematic reviews including statistical pooling of individual study findings may achieve greater statistical power and external 
validity than single studies alone [11], we aimed to perform a comprehensive systematic review and meta-analysis of studies comparing right versus left radial access for diagnostic or interventional coronary procedures.

\section{Methods}

2.1. Study design

The present review was performed according to the Cochrane Collaboration and PRISMA statements $[12,13]$. In addition, it was prospectively registered on www. metcardio.org (protocol \#2/2010).

\subsection{Search strategy}

CENTRAL, Google Scholar, MEDLINE/PubMed and Scopus were searched by two independent reviewers (GBZ, ML) for studies comparing right versus left radial access for diagnostic or interventional coronary procedures published up to 15 April, 2011. In particular MEDLINE/PubMed was searched according to Biondi-Zoccai et al. [14] with the following strategy: right AND left AND (radial OR ulnar) AND coronary AND (randomized controlled trial[pt] OR controlled clinical trial[pt] OR randomized controlled trials[mh] OR random allocation[mh] OR double-blind method[mh] OR single-blind method[mh] OR clinical trial[pt] OR clinical trials[mh] OR (clinical trial[tw] OR ( $(\operatorname{singl} *[\mathrm{tw}]$ OR doubl $*[\mathrm{tw}]$ OR trebl $*[\mathrm{tw}]$ OR tripl $*[\mathrm{tw}])$ AND (mask $*[\mathrm{tw}]$ OR blind [tw])) OR (latin square[tw]) OR placebos[mh] OR placebo $*[\mathrm{tw}]$ OR random $*[\mathrm{tw}] \mathrm{OR}$ research design[mh:noexp] OR follow-up studies[mh] OR prospective studies[mh] OR cross-over studies[mh] OR control $*$ [tw] OR prospectiv $*[$ tw] OR volunteer $*[$ tw] $)$ NOT (animal[mh] NOT human[mh]) NOT (comment[pt] OR editorial[pt] OR metaanalysis[pt] OR practice-guideline[pt] OR review[pt])).

References of retrieved studies were checked for additional studies (backward snowballing) and 2008-2011 conference proceedings of the American College of Cardiology, American Heart Association, European Society of Cardiology, and Transcatheter Cardiovascular Therapeutics scientific sessions were also manually searched. No language restriction was enforced.

\subsection{Study selection}

Citations were first scanned at the title/abstract level. Shortlisted studies were then retrieved in full text and appraised according to the following criteria. Inclusion criteria were as follows (all had to be met for inclusion): inclusion of patients undergoing diagnostic or interventional coronary procedures; by means of right or left radial artery access; and with randomized treatment allocation. Exclusion criteria were as follows (one was sufficient for study exclusion): duplicate publication; and randomized treatment allocation not focused on right versus left access. Study selection was performed by two independent reviewers (GBZ, ML), with divergences resolved by consensus.

\subsection{Data abstraction and validity assessment}

The followed data were abstracted from retrieved studies by two independent reviewers (GBZ, ML), with divergences resolved by consensus: location, patients, primary end-point, females, diabetes mellitus, acute coronary syndromes, percutaneous coronary intervention, Allen test, sequence generation, allocation concealment, blinding, data outcome completion, reporting features, procedural time (minutes), contrast use $(\mathrm{mL})$, fluoroscopy time (seconds), cross-over to femoral access, in-hospital death, myocardial infarction, stroke, and major bleeding as per Thrombolysis in Myocardial Infarction (TIMI) definitions, as well as the composite end-point of in-hospital death, myocardial infarction, stroke, or major bleeding. In addition, all corresponding authors of shortlisted studies were directly queried for missing or unclear data. Validity features were appraised according to the Cochrane Collaboration [12]

\subsection{Data analysis}

Continuous variables are reported as mean (standard deviation) or median (range), when appropriate. In case of missing values for standard deviations and lack of replies to direct queries to corresponding authors, these were imputed according to normal distribution assumptions, where mean $\pm 0.6745 *$ standard deviation equals to $1 \mathrm{st}-3$ rd quartiles. Categorical variables are expressed as $\mathrm{n} / \mathrm{N}$ (\%). Statistical pooling was performed computing risk ratios (RR) for categorical variables and weighted mean differences (WMD) for continuous variables, both with $95 \%$ confidence intervals. Statistical homogeneity was tested with the $\chi^{2}$ test and consistency with $\mathrm{I}^{2}$ [12]. In case of $\mathrm{I}^{2}>50 \%$ (suggesting substantial inconsistency), a random-effect model was used as this provides larger and more conservative confidence intervals. Conversely, in case of $\mathrm{I}^{2}<50 \%$ (suggesting mild or moderate inconsistency), a fixed-effect model was used as this provides more precise estimates and lends more statistical weight to larger studies. Small study effects (including publication bias) were appraised with graphical inspection of funnel plots. Unadjusted p values are reported throughout, with hypothesis testing set at the two-tailed 0.05 level. Computations were performed with RevMan 4.3 (The Cochrane Collaboration, Copenhagen, Denmark).

\section{Results}

\subsection{Included studies}

From a total of 9216 citations, 5 randomized trials were finally included (Fig. 1) [9,10], [15-17]. These studies were conducted in Italy, Japan, Spain, and USA, were published between 2004 and 2011, and included a total 3210 patients (Table 1). Most procedures were diagnostic coronary angiographies, with PCI performed during the same procedure in $32.5 \%$ of patients. Notably, subjects were enrolled only after proof of a normal Allen test, despite recent suggestions that this may not be mandatory in clinical practice $[18,19]$.

Appraisal of the internal validity of included studies suggested a moderate to low risk of bias, despite the obvious lack of patient or physician blinding (Table 2). Nonetheless, in 2 studies means for generation of allocation sequence were not mentioned $[9,15]$, whereas Kanei et al. used a pseudorandomization scheme [17].

\subsection{Meta-analysis}

Pooled analyses (Figs. 2-5) demonstrated that right radial access was associated with similar procedural time (random-effect WMD $=0.99$ $[-0.53 ; 2.51] \mathrm{min}, \mathrm{p}$ for effect $=0.20, \mathrm{p}$ for heterogeneity $<0.001$, $\mathrm{I}^{2}=79 \%$ ), contrast use (fixed-effect WMD $=1.71[-1.32 ; 4.74] \mathrm{mL}, \mathrm{p}$ for effect $=0.27$, p for heterogeneity $=0.28, \mathrm{I}^{2}=22 \%$ ), and fluoroscopy time (random-effect WMD $=35.79[-3.54 ; 75.12] \mathrm{s}$, p for effect $=0.07$, $\mathrm{p}$ for heterogeneity $<0.001, \mathrm{I}^{2}=80 \%$ ). However, right radial access was apparently inferior to left radial access in terms of access site failure leading to cross-over to femoral access (5.2\% versus 3.1\%, fixed-effect $\mathrm{RR}=1.65[1.18 ; 2.30], \mathrm{p}$ for effect $=0.003$, $\mathrm{p}$ for heterogeneity $=0.25$, $\left.\mathrm{I}^{2}=25 \%\right)$.

In terms of patient-relevant outcomes, right and left radial showed similar risks of death $(0.3 \%$ versus $0.2 \%$, fixed-effect $\mathrm{RR}=2.00[0.37 ; 10.89]$, $\mathrm{p}$ for effect $=0.42, \mathrm{p}$ for heterogeneity $=1.0$, $\left.\mathrm{I}^{2}=0\right)$, myocardial infarction $(0.3 \%$ versus $0.3 \%$, fixed-effect $\mathrm{RR}=1.33[0.30 ; 5.94], \mathrm{p}$ for effect $=0.71, \mathrm{p}$ for heterogeneity $=0.66$, $\left.\mathrm{I}^{2}=0\right)$, stroke $(0.1 \%$ versus 0 , fixed-effect $\mathrm{RR}=3.00$ [0.12; 73.53], $\mathrm{p}$ for effect $=0.50, \mathrm{p}$ for heterogeneity $\left.=1.0, \mathrm{I}^{2}=0\right)$, major bleeding $(0.3 \%$ versus $0.1 \%$, fixed-effect $R R=3.00[0.31 ; 28.78]$, p for effect $=$ 0.34 , $\mathrm{p}$ for heterogeneity $=1.0, \mathrm{I}^{2}=0$ ), or their composite end-point (1.0\% versus $0.5 \%$, fixed-effect $R R=2.00[0.75 ; 5.31]$, $\mathrm{p}$ for effect $=$ 0.16 , $\mathrm{p}$ for heterogeneity $=0.49, \mathrm{I}^{2}=0$ ).

The association between fluoroscopy time, radial access, and crossover rate was formally tested with exploratory meta-regression, without statistically significant results $(\mathrm{p}=0.450)$. However, this analysis is strongly limited by the few included studies. Exploration for small

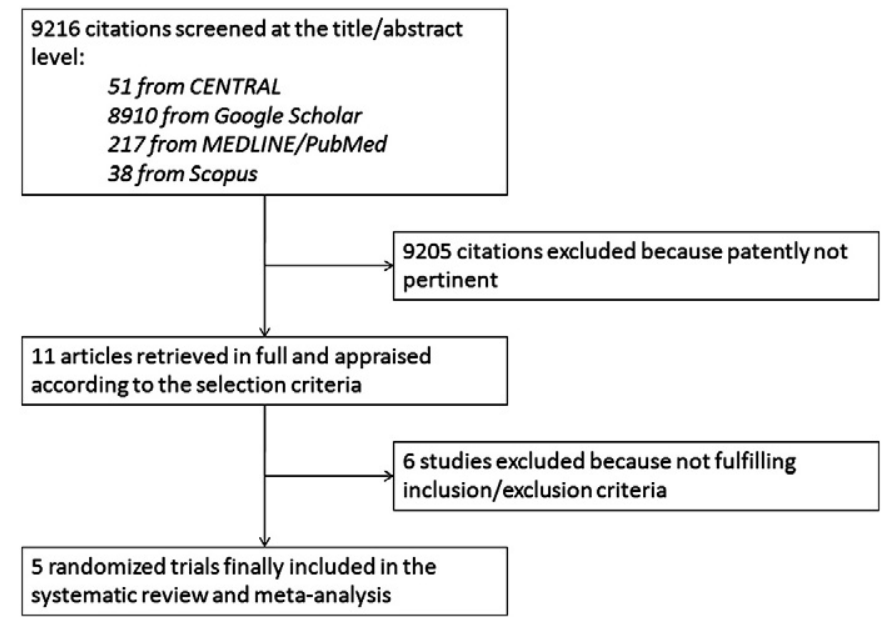

Fig. 1. Review profile. 
Table 1

Main features of included studies.

\begin{tabular}{|c|c|c|c|c|c|c|c|c|}
\hline Study & Location & Patients & Primary end-point & Females (\%) & $\mathrm{DM}(\%)$ & $\operatorname{ACS}(\%)$ & PCI (\%) & $\begin{array}{l}\text { Preliminary } \\
\text { Allen test }\end{array}$ \\
\hline $\begin{array}{l}\text { Fernández-Portales (2006) } \\
\text { [15] }\end{array}$ & Spain & 364 & Not specified & 31 & 34 & Not reported & 28 & Mandatory \\
\hline Kanei (2011) [17] & USA & 193 & $\begin{array}{l}\text { Procedural difficulty (hydrophilic/coronary wire use for } \\
\text { tortuosity, stiff wire use for the coronary engagement, } \\
>2 \text { catheters use, or nonselective injection) }\end{array}$ & 48 & 37 & Not reported & 22 & Mandatory \\
\hline Kawashima (2004) [9] & Japan & 443 & Not specified & 45 & 23 & Not reported & Not reported & Mandatory \\
\hline Santas (2009) [16] & Spain & 670 & Procedural success & 30 & 35 & Not reported & 37 & Mandatory \\
\hline Sciahbasi (2011) [10] & Italy & 1540 & Fluoroscopy time & 32 & 29 & 46 & 47 & Mandatory \\
\hline
\end{tabular}

ACS $=$ acute coronary syndromes; $\mathrm{DM}=$ diabetes mellitus; $\mathrm{PCI}=$ percutaneous coronary intervention.

Table 2

Internal validity of included studies.

\begin{tabular}{|c|c|c|c|c|c|c|}
\hline Study & Adequate sequence generation? & $\begin{array}{l}\text { Allocation } \\
\text { concealment? }\end{array}$ & Blinding? & $\begin{array}{l}\text { Incomplete data } \\
\text { outcome addressed? }\end{array}$ & $\begin{array}{l}\text { Free of selective } \\
\text { reporting? }\end{array}$ & $\begin{array}{l}\text { Free of } \\
\text { other bias? }\end{array}$ \\
\hline $\begin{array}{l}\text { Fernández-Portales (2006) } \\
\text { [15] }\end{array}$ & Not reported & Not reported & No & No & No & Yes \\
\hline Kanei (2011) [17] & $\begin{array}{l}\text { No ("After informed consent, patients were randomized to the } \\
\text { right radial or left radial approach on the basis of medical } \\
\text { record number") }\end{array}$ & No & No & No & Yes & Yes \\
\hline Kawashima (2004) [9] & Not reported & Not reported & No & No & No & Yes \\
\hline Santas (2009) [16] & Yes & Yes & No & Yes & Yes & Yes \\
\hline Sciahbasi (2011) [10] & Yes & Yes & No & Yes & Yes & Yes \\
\hline
\end{tabular}

study effects and publication bias did not disclose any evidence of such phenomena (Fig. 6). However, the small number of studies also limits the power of such analyses.

\section{Discussion}

\subsection{Overall findings}

This systematic review and meta-analysis is, to the best of our knowledge, the first to compare right versus left radial access in patients undergoing percutaneous diagnostic or interventional procedures [20,21]. Our main original findings are: a) both right and left radial accesses are equally safe and effective; b) neither right nor left radial access appears significantly better than the other in terms of procedural duration, contrast use, fluoroscopy time or clinically relevant end-points; c) nonetheless, left radial access is associated with fewer failures leading to cross-over to femoral access; d) thus, left radial should be preferred by inexperienced operators or when wishing to minimize risk of cross-over to femoral access.

\subsection{Current clinical and research context}

Radial access is most likely to become the standard access site for diagnostic and interventional coronary procedures given its major clinical benefits in comparison to femoral or brachial accesses [2-5], [8]. Specifically, Agostoni et al. have previously demonstrated in a meta-analysis including 3224 patients that radial access is associated with similar rates of major adverse cardiac events in comparison to femoral access, but much fewer access site complications (odds ratio $=0.20, \mathrm{p}<0.001$ ) [3]. A more comprehensive review by Jolly et al. demonstrated that radial access significantly reduces major bleeding and hospital stay, with numerical yet statistically non-significant reductions in death and the composite of death, myocardial infarction, or stroke [4]. Similar findings have been reported also by the RIVAL trial investigators among 7021 subjects with acute coronary syndromes, where radial access was associated with a significantly lower rate of major vascular complications (hazard ratio $=0.37$, $\mathrm{p}<0.001$ ) and ACUITY-defined major bleedings (hazard ratio $=0.43$, $\mathrm{p}<0.001$ ), albeit at the expense of more access site cross-overs (hazard ratio $=3.8, \mathrm{p}<0.001$ ) [5].

Despite substantial evidence in favor of radial access in general, debate continues on which radial artery should be targeted [22]. Indeed, whereas most operators prefer right radial access for comfort reasons, left radial access ensures catheter maneuvers which are more similar to those required with femoral access [23]. Yet, it remains unclear whether right radial access is equivalent or inferior to left radial access in the hands of experienced operators.

\subsection{Implications of the present study}

This systematic review and meta-analysis builds upon recent evidence in support of the safety and efficacy of radial artery access [35], and provides clinically relevant suggestions on which radial access should be chosen. Indeed, right and left radial access proved similar in

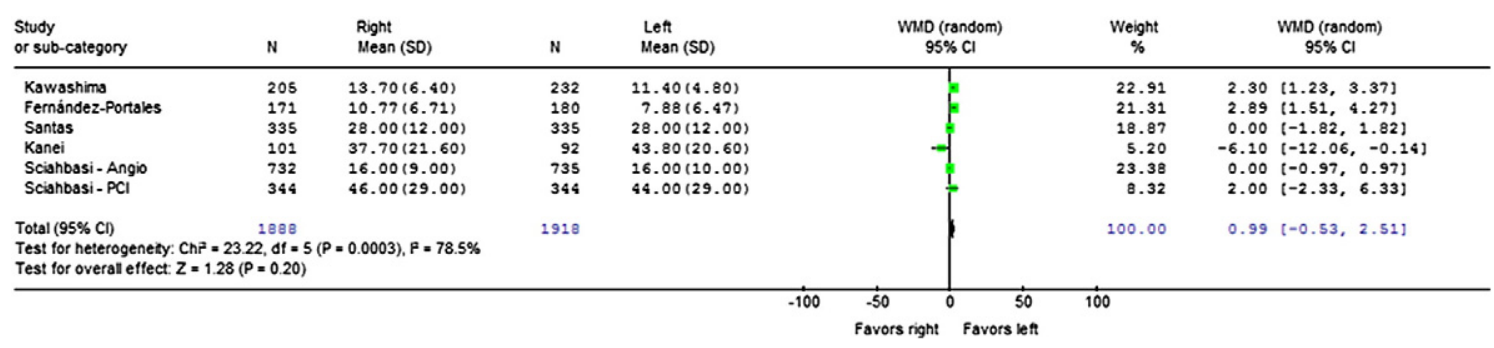

Fig. 2. Forest plot for procedural time (minutes). $\mathrm{CI}=$ confidence interval; $\mathrm{df}=$ degrees of freedom; $\mathrm{SD}=\mathrm{standard}$ deviation; $\mathrm{WMD}=$ weighted mean difference. 


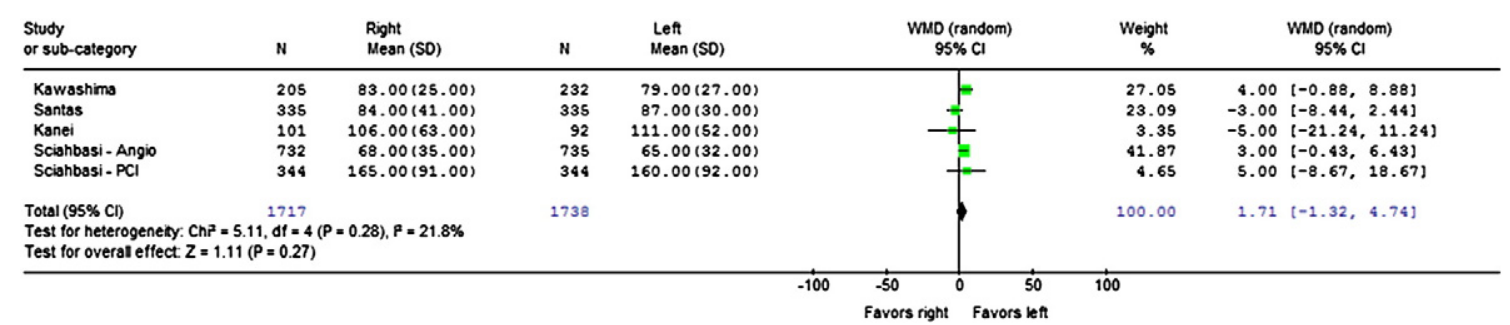

Fig. 3. Forest plot for contrast use $(\mathrm{mL}) . \mathrm{Cl}=$ confidence interval; $\mathrm{df}=$ degrees of freedom; $\mathrm{SD}=$ standard deviation; $\mathrm{WMD}=$ weighted mean difference.

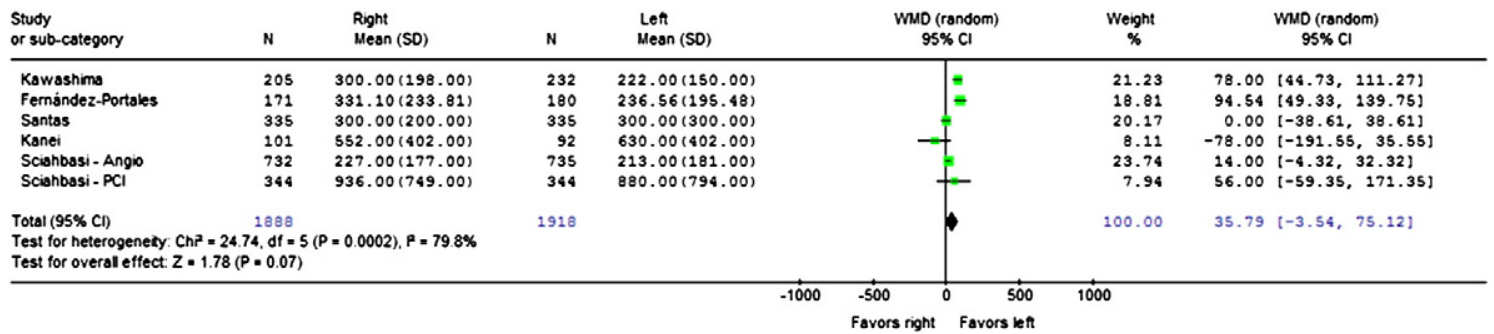

Fig. 4. Forest plot for fluoroscopy time (seconds). $\mathrm{CI}=$ confidence interval; df = degrees of freedom; $\mathrm{SD}=$ standard deviation; WMD = weighted mean difference.

terms of clinical outcomes, procedure duration, and contrast volume. However, right radial access appeared inferior to left radial access in terms of need for femoral cross-over (5.2\% versus $3.1 \%$, respectively). The strong, albeit non-significant trend ( $p=0.07$ ), of lower fluoroscopy times in the left radial access group also supports a superiority of this access site. An absolute $2 \%$ difference in the risk of cross-over may not appear striking, but in relative terms it translates into a relative risk reduction of $40 \%$, when a left radial access is chosen instead of a right radial access. In addition, we can expect higher overall rates of radial failure by inexperienced operators, and thus larger benefits from using a left radial access. Indeed, it is conceivable that most operators involved in the included studies were highly experienced and thus at an overall low risk of radial failure.

Whereas our personal preference goes almost invariably to right radial or ulnar access, mainly because of greater operator comfort [6,7], [19], we can thus suggest radial beginners to systematically adopt left radial access until they reach a substantial expertise in transradial procedures. Once their learning curve is complete and their transradial skills refined, both right and left radial accesses can be used. Nonetheless, left radial access could still be recommended even to expert radialists when wishing to minimize radiation exposure (e.g. in women with childbearing potential) or risk of crossover to femoral access (e.g. in patients with international normalized ratio $>2.0$ ). Another setting in which left radial access should be the first choice is the patient with prior coronary artery bypass grafting requiring selective angiography of saphenous vein grafts originating from the anterior wall of the ascending aorta or left internal mammary artery grafts $[24,25]$.

\subsection{Avenues for further research}

Further and larger randomized studies comparing right versus left radial access are welcome and would surely improve the statistical precision of the quantitative estimates hereby provided. However, they would not be likely to substantially change the main findings of our review. Nonetheless, further issues worth researching include the appraisal of a total wrist access strategy (attempting both ipsilateral radial and ulnar accesses before moving to the contralateral radial or ulnar arteries) [19]. Whereas fluoroscopy time is easily collected, it has a very limited usefulness to estimate radiation exposure. Indeed, fluoroscopy times are just general and indirect indicators of the radiation produced by X-ray machinery therefore no direct inference can be made regarding operators exposure, which needs a specific recording of personal absorption in different zones of the body of operators, over and below the surface of the apron. The weight of patients in this context is also a major determinant of operator's exposure. In addition, dose area product (DAP) and air kerma are much more clinically relevant measures of radiation exposure. Unfortunately, the above data were not systematically collected and analyzed in the included studies, and thus they are beyond the scope of our work. Further trials should focus in greater details on these key aspects.

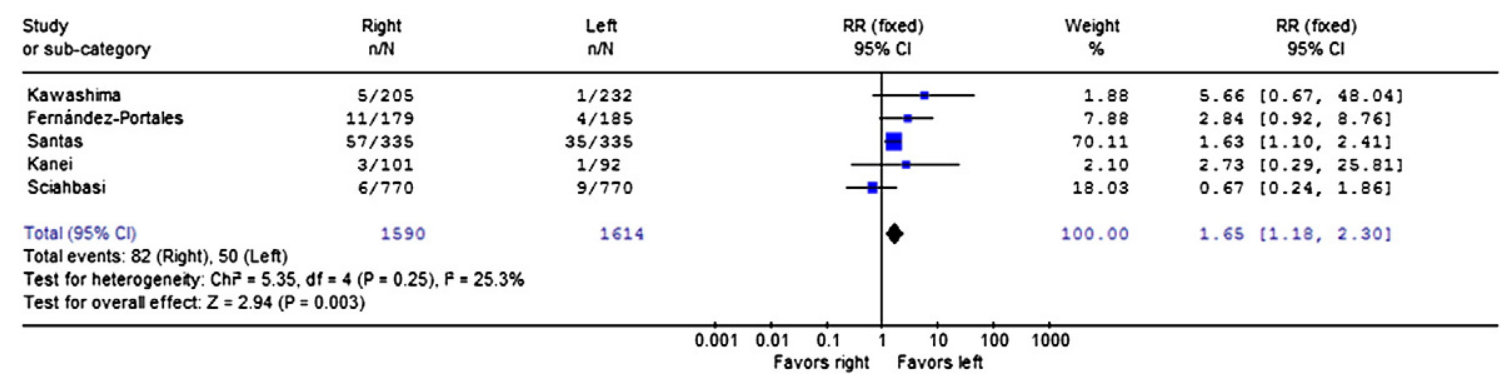

Fig. 5. Forest plot for radial failure leading to cross-over to femoral access. $\mathrm{CI}=$ confidence interval; $\mathrm{df}=$ degrees of freedom; $\mathrm{RR}=$ risk ratio. 


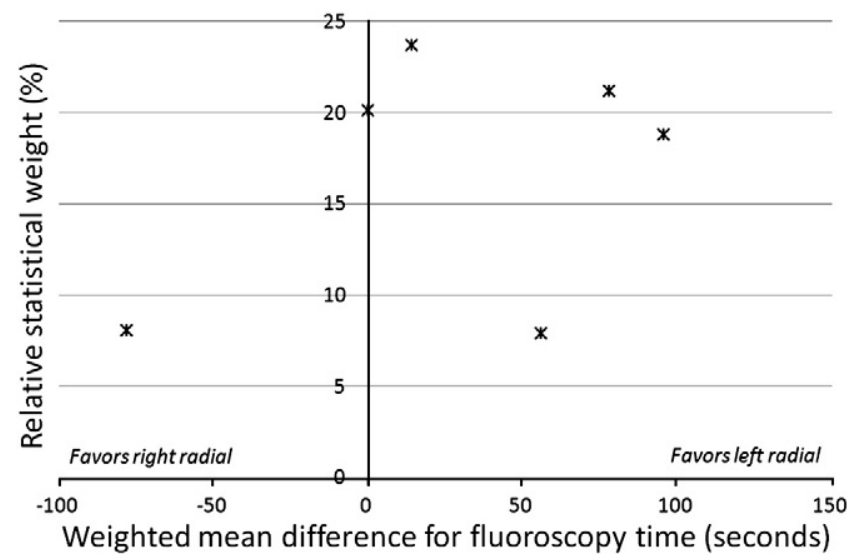

Fig. 6. Funnel plot for fluoroscopy time (seconds).

\subsection{Limitations}

This systematic review is fraught with the typical limitations of meta-analyses [26]. More specifically, the small number of included studies, the reliance on end-points with limited patient relevance (such as procedural time) and the statistical inconsistency underlying several sub-analyses appear as major drawbacks of this work. Nonetheless, inclusion of randomized trials only and systematic queries to corresponding authors for data checking strengthen the overall validity and robustness of our work. On the other hand, randomized trials maximize internal validity at the expense of external validity. Thus, reliance only on highly selective randomized trials limits the external validity of our findings, which can be reinforced only by carefully conducted yet comprehensive observational studies. Another drawback of our work is the lack of focus on the importance of operator experience and volume and their impact on procedural outcomes of radial access. Indeed, no data on operator experience/ volume could be extracted from the included studies, and thus formal analysis of this important aspect was beyond the scope of our work. Nonetheless, we can safely state, based on both personal extensive experience in radial access and medical literature $[3,19]$, that left radial access can be considered more suitable to operators already trained in femoral access but with experience in radial procedures, mainly because left radial access entails more favorable catheter geometry than right radial access. Finally, the apparent mismatch between the higher cross-over rate to femoral access with right radial access and procedural duration, contrast administration and fluoroscopy time might be explained by several factors. First, operators might have different thresholds to shift from radial to femoral when using a right versus left access, with the latter being discontinued only after more and repeated attempts. In addition, the extreme variability and lack of Gaussian distribution of procedural duration, contrast administration and fluoroscopy time may limit the precision and statistical power of their pooled analysis. Finally, as always in biostatistics, statistical significance is proof of effect, but lack of statistical significance cannot be considered proof of lack of effect, but rather only as lack of proof of effect [27].

\section{Conclusions}

Right and left radial accesses appear largely similar in their overall procedural and clinical performance during transradial diagnostic or interventional procedures. Nonetheless, left radial access can be recommended especially during the learning curve phase to reduce femoral cross-overs.

\section{Funding}

None.

\section{Conflict of interest}

None.

\section{Acknowledgments}

The authors of this manuscript have certified that they comply with the Principles of Ethical Publishing in the International Journal of Cardiology.

\section{References}

[1] Campeau L. Percutaneous radial artery approach for coronary angiography. Cathet Cardiovasc Diagn 1989;16:3-7.

[2] Kiemeneij F, Laarman GJ, Odekerken D, Slagboom T, van der Wieken R. A randomized comparison of percutaneous transluminal coronary angioplasty by the radial, brachial and femoral appproaches: the Access study. J Am Coll Cardiol 1997;29: 1269-75.

[3] Agostoni P, Biondi-Zoccai GG, de Benedictis ML, Rigattieri S, Turri M, Anselmi M, et al. Radial versus femoral approach for percutaneous coronary diagnostic and interventional procedures; Systematic overview and meta-analysis of randomized trials. J Am Coll Cardiol 2004;44:349-56.

[4] Jolly SS, Amlani S, Hamon M, Yusuf S, Mehta SR. Radial versus femoral access for coronary angiography or intervention and the impact on major bleeding and ischemic events: a systematic review and meta-analysis of randomized trials. Am Heart J 2009;157:132-40.

[5] Jolly SS, Yusuf S, Cairns J, Niemelä K, Xavier D, Widimsky P, et al. RIVAL trial group. Radial versus femoral access for coronary angiography and intervention in patients with acute coronary syndromes (RIVAL): a randomised, parallel group, multicentre trial. Lancet 2011;377:1409-20.

[6] Aptecar E, Pernes JM, Chabane-Chaouch M, Bussy N, Catarino G, Shahmir A, et al. Transulnar versus transradial artery approach for coronary angioplasty: the PCVI-CUBA study. Catheter Cardiovasc Interv 2006;67:711-20.

[7] Biondi-Zoccai GG, Moretti C, Omedè P, Sciuto F, Agostoni P, Romagnoli E, et al Intra-arterial lidocaine versus saline to reduce peri-procedural discomfort in patients undergoing percutaneous trans-radial or trans-ulnar coronary procedures. Acta Cardiol 2011;66:9-14.

[8] Vorobcsuk A, Kónyi A, Aradi D, Horváth IG, Ungi I, Louvard Y, et al. Transradial versus transfemoral percutaneous coronary intervention in acute myocardial infarction systematic overview and meta-analysis. Am Heart J 2009;158:814-21.

[9] Kawashima O, Endoh N, Terashima M, Ito Y, Abe S, Ootomo T, et al. Effectiveness of right or left radial approach for coronary angiography. Catheter Cardiovasc Interv 2004;61:333-7.

[10] Sciahbasi A, Romagnoli E, Burzotta F, Trani C, Sarandrea A, Summaria F, et al. Transradial approach (left vs right) and procedural times during percutaneous coronary procedures: TALENT study. Am Heart J 2011;161:172-9.

[11] Biondi-Zoccai GG, Abbate A, Sheiban I. Systematic reviews and meta-analyses "For Dummies". EuroIntervention 2009;5:289-91.

[12] Higgins JPT, Green S. Cochrane Handbook for Systematic Reviews of Interventions. Oxford: The Cochrane Collaboration; 2008.

[13] Liberati A, Altman DG, Tetzlaff J, Mulrow C, Gøtzsche PC, Ioannidis JP, et al. The PRISMA statement for reporting systematic reviews and meta-analyses of studies that evaluate healthcare interventions: explanation and elaboration. BMJ 2009;339:b2700.

[14] Biondi-Zoccai GG, Agostoni P, Abbate A, Testa L, Burzotta F. A simple hint to improve Robinson and Dickersin's highly sensitive PubMed search strategy for controlled clinical trials. Int J Epidemiol 2005;34:224-5.

[15] Fernández-Portales J, Valdesuso R, Carreras R, Jiménez-Candil J, Serrador A, Romaní S. Right versus left radial artery approach for coronary angiography. Differences observed and the learning curve. Rev Esp Cardiol 2006;59:1071-4.

[16] Santas E, Bodi V, Sanchis J, Nunez J, Mainar L, Minana G, et al. The left radial approach in daily practice. A randomized study comparing femoral and right and left radial approaches. Rev Esp Cardiol 2009;62:482-90.

[17] Kanei Y, Nakra NC, Liou M, Vales LL, Gowda R, Rosero H, et al. Randomized comparison of transradial coronary angiography via right or left radial artery approaches. Am J Cardiol 2011;107:195-7.

[18] Ghuran AV, Dixon G, Holmberg S, de Belder A, Hildick-Smith D. Transradial coronary intervention without pre-screening for a dual palmar blood supply. Int J Cardiol 2007:121:320-2.

[19] Biondi-Zoccai G, Moretti C, Zuffi A, Agostoni P, Romagnoli E, Sangiorgi G. Transradial access without preliminary allen test-letter of comment on Rhyne et al. Catheter Cardiovasc Interv 2011;78:662-3.

[20] Database of Abstracts of Reviews of Effects (DARE). Available at:http://www.crd. york.ac.uk/CMS2Web last accessed on 22 April, 2011.

[21] International Prospective Register of Systematic Reviews (PROSPERO). Available athttp://www.crd.york.ac.uk/prospero last accessed on 22 April, 2011. 
[22] Louvard Y, Lefèvre T, Allain A, Morice M. Coronary angiography through the radial or the femoral approach: the CARAFE study. Catheter Cardiovasc Interv 2001;52: $181-7$.

[23] Hamon M, McFadden E. Trans-radial Approach for Cardiovascular Interventions. Paris: ESM; 2003.

[24] Burzotta F, Trani C, Hamon M, Amoroso G, Kiemeneij F. Transradial approach for coronary angiography and interventions in patients with coronary bypass grafts: tips and tricks. Catheter Cardiovasc Interv 2008;72:263-72.

[25] Burzotta F, Trani C, Todaro D, Romagnoli E, Niccoli G, Ginnico F, et al. Comparison of the transradial and transfemoral approaches for coronary angiographic evaluation in patients with internal mammary artery grafts. J Cardiovasc Med (Hagerstown) 2008;9:263-6.

[26] Biondi-Zoccai GG, Lotrionte M, Abbate A, Testa L, Remigi E, Burzotta F, et al. Compliance with QUOROM and quality of reporting of overlapping meta-analyses on the role of acetylcysteine in the prevention of contrast associated nephropathy: case study. BMJ 2006;332:202-9.

[27] Biondi-Zoccai G, Romagnoli E, Agostoni P, Capodanno D, Castagno D, D'Ascenzo F, et al. Are propensity scores really superior to standard multivariable analysis? Contemp Clin Trials 2011;32:731-40. 